\title{
Topónimos de la cuenca del río Tambopata (Puno) $^{1}$
}

\author{
Toponyms of the Tambopata River Basin (Puno)
}

\author{
Felipe Huayhua Pari \\ Dpto. Acad. de Lingüística \\ CILA-FLCH-UNMSM \\ fhuayhua@gmail.com
}

\begin{abstract}
Resumen
En este artículo presentamos los topónimos de la cuenca del río Tambopata en la región de Puno. Constituye solo una parte del estudio más amplio que hemos realizado sobre el léxico de nombres de lugares, plantas, animales, enfermedades y objetos recogidos en la cuenca del río Tambopata que comprende en su recorrido a tres distritos de la Prov. de Sandia: Yanahuaya, San Juan del oro y Putina Punco.

Se analizó lingüísticamente (fonología, léxico y semántica) la variación de los nombres que están relacionados con la lengua que hablan en la zona. Así mismo, se aplicó la teoría de la variación dialectal y el método de geografía lingüística o geolingüística para levantar isoglosas, con un enfoque descriptivo - interpretativo inspirado en la lingüística estructural y funcional.

Se ha probado la hipótesis planteada, que el abandono de la lengua y cultura es lenta. El objetivo del estudio es mostrar la dialectalización del aimara y los patrones de denotación y connotación. Este estudio servirá para elaborar la cartografía lingüística, diccionarios regionales. Así también contribuirá con el conocimiento de los saberes andinos que está presente en este avance cultural, asimismo fortalecerá la interculturalidad.
\end{abstract}

Palabras clave: Aimara, Tambopata, variación dialectal, toponimia.

\begin{abstract}
In this article we present the place names of the Tambopata river basin in the Puno region. It constitutes only part of the broader study that we have carried out on the lexicon of place names, plants, animals, diseases and objects collected in the Tambopata river basin, which includes three districts in the province of Sandia: Yanahuaya, San Juan del oro and Putina in the province of Sandia.

We analize linguistically - phonologically, lexically and semantically - the variation of the names related to the local language. BesideThe theory of dialectal variation, the method of linguistic geography or geolinguistics are applied to lift isoglosas with descriptive and interpretative focus, inspired in descriptive and functional linguistics.

The hypothesis set up has been proven that the language and culture has being abandoned slowly. The aim of this study was to prove the dialectization of Aymara language, denotation and connotation patterns. This study will help the elaboration of linguistic cathegories, regional linguistic dictionaries. As well it will contribute to the knowledge of Andean wisdom that are current in the culture, and will veriforce the interculturality.
\end{abstract}

Keywords: Aymara, Tampobata, dialectal variation, toponimy,

1 Este trabajo es una parte de un estudio léxico sobre nombres de lugares, plantas, animales y objetos pertenecientes a la cuenca del río Tambopata, donde se acopió alrededor de 450 entradas. 
Felipe Huayhua Pari

\section{Introducción}

Un antecedente de estudios antropológicos tenemos en la obra de Héctor Martínez, Las migraciones altiplánicas y la colonización del Tambopata, primero como tesis (1958) y luego en forma ampliada que publicó en 1969, relata los hechos socioeconómicos, recursos y situaciones del migrante que resumimos así, el lugar recibe varias denominaciones como Valle de Tambopata, colonización en la «Montaña amazónica», ésta responde a las preguntas ¿De dónde, quienes, cuántos, porqué migran?, ¡¿Qué formas de vida tiene y qué problemas enfrentan en el nuevo habitat?. En el aspecto socio-cultural del altiplano, observa que Puno tiene altiplano y montaña que está dividido por la Cordillera de Carabaya en el primero están Huancané, Moho, Chucuito, Puno, Azángaro, Lampa y en el segundo está Carabaya y Sandia, éste último como una solución natural para los aimaras del altiplano que sufren la parcelación, juicios de sus tierras. El lugar de procedencia de los migrantes es principalmente de Conima y la lengua de la mayoría de estos es el aimara. Como antecedentes de la migración señala que desde la conquista ingresan a Carabaya y Sandia en busca de oro, incluso de Caballuni envían a España un monolito de oro de 4 kilos después el pueblo desaparece. Llega la época de Cascarilla visitaron al lugar Weddell, Markham y Raimondi para estudiar, conocer esa planta hasta 1860, aunque en 1835 aparece muertos por los «chunchos» una mujer y un indio, que después escapan hacía chunchusmayo. Aparece la época del Caucho de 1739 a 1930 a raíz del invento del vulcanización de Goodyear, los caucheros "gomeros» penetran a Tambopata y construyen caminos de herradura desde Sandia a San Juan de Tambopata $(85 \mathrm{~km})$, de San Juan de Tambopata a Marte (130 km) (Guevara, 1955, p. 1145).

Después decae la fiebre del caucho, viene la época de la coca es perene. Llegó la época de café cuando España prohibe a Brasil su comercialización, encuentran en Tambopata un café natural. El levantamiento de Huanamé en 1923 ocasiono jugos a la selva de Puno para no ser aniquilados por los mestizos luego en 1935 cuando encuentran petróleo en el Chaco Boreal (antes Bolivia), se desata la «Guerra de Chaco», al ser vencidos, los bolivianos muchos migrantes de los Valles de Bolivia regresan a Conima, luego en 1952 a raíz de la «Revolución Boliviana» que obligó la nacionalización de los peruanos residentes en dicho país ellos retornan dejando su mujer, hijos bolivianos; pero al llegar a Conima son despectivamente llamados «yungeño», por estas razones comienza una avalancha colonizadora entre 1938 a 1940 hacía la selva de Puno, conocido como «ombligo de la primera colonización 
Topónimos de la cuenca del río Tambopata (Puno)

indígena» después como la «Segunda unidad de colonización indígena» (Guevara, 1955, p. 1142; Metraux, 1954; Luna, 1954), es una migración interna dentro del mismo departamento, primero llegan a pie en siete días desde Conima porque la carretera solo existió de Juliaca a Sandia (1956) después llega la carretera a San Juan del oro en 1967, en 1969 hasta 2 km de yanamayo, en 1970 a Putina Punco y en la actualidad (2011) a Azata, San Carlos, Victoria, así los 285 km, que antes llegaban en 7 días, a pie 2 días en camión se llega en 21 horas.

Con respecto a los colonizadores Martínez encuentra 562 personas de Conima que representa $142.6 \%$ con los niños suma 640 de los cuales 411 son varones y 239 mujeres, ellos están más integrados porque se identifican como «tambopatiños» a pesar de que hay tres estratos sociales: mestizo, indígena y cholo en cada una hay ricos, medianos y pobres, dice hay cholización «Es posible que dentro de una generación se había completado este proceso y en el valle quedarán muy pocos indígenas, los más ancianos, al ser reemplazado por los cholos» (Martínez, 1969, p. 190).

Con respecto a la lengua dice que el aimara es más dominante el $44.3 \%$, y Quechua es 32.3\% (Martínez, 1969, p. 240). Así podemos ver por el lugar en San Juan del Oro, Chaylluma, Yanamayo Pablobamba, Putina Punco, Chocal, Pampa Grande y Azata son aimaras y en yanahuaya, yurajmayo, sicuni, lagunillas son aimaras y quechuas, incluso sólo aimaras en Pampa Grande y Azata.

Los aimaras se dedican más al cultivo de café, los quechuas al comercio, cargadores, peones. Los sectores aimaras han desarrollado más rápido que los pobladores quechuas. Los aimaras han introducido a la selva de Puno su cultura, su lengua, sus saberes, costumbres y lo que aprendieron en los valles de Bolivia; aunque poco en la religión, curanderismo porque los ancianos no van a la selva por las caminatas tan largos. Últimamente dice Martínez que la composición de los colonizadores es, de los 4857 colonos que hay en el Valle de Tambopata, $55.8 \%$ proceden de los disitritos aimaras de Conima y Moho y el $17.3 \%$ de los distritos quechuas de Putina y Chuma (Guevara, 1955, p. 252).

Finalmente Martínez presenta un glosario de 164 términos de animales, plantas, minerales, objetos, autoridades y 69 topónimos, trata de describir su significado origen ya sea aimara o quechua o si es regionalismo o regional.

Otras referencias de viajes, historias, exploraciones, monografías tenemos en: Raimondi (1860), Vellalta (1907), Carbajal (1908), Stiglich (1908), Luna (1954), Metraux (1954), Guevarra (1955) Chichón (1977) Turpo (2010), Calizaya (2006). 


\section{Felipe Huayhua Pari}

\section{Materiales y metodos}

El corpus del presente trabajo esta constituido por los nombres geográficos o topónimos de la zona en cuestión lo cual incluye los nombres de cerro o accidentes geográficos agua, centros poblados de mayor o menor envergadura de restos arqueológicos, etc. este corpus fue recogido en varios trabajos de campo uno por treinta días el marzo de dos mil doce, el otro en nueve meses en el año de mil novecientos sesenta y nueve y las entrevistas a Marcelino Chambi, Escolastico Huayhua y Alberto Choquechambi.

\section{Objetivos}

a. Realizar un estudio de la variación lingüística de la Lengua aimara de la selva de Puno (San Juan del Oro), Tambopata y la isoglosas que separan en la zonificación.

b. Elaborar un glosario de elementos culturales, toponimias de la región tomando en cuenta la entrada léxica, categoría gramatical, transcripción fonética, nombre científica de la planta, animal, nombre vulgar, la glosa su definición, ejemplos de forma y función (fotos, filmaciones) en ese orden.

\section{Resultados}

\subsection{Exposición, sistematización e interpretación de los resultados logrados}

Descripción onomástica: Comprende los topónimos distribuidos según su ámbito geográfico de procedencia.

\subsubsection{Descripción de lugares de Alto Tambopata en versión castellana, aimara, quechua y otra lengua}

Para esta descripción se organizó el espacio toponímico en seis subáreas: a) margen izquierda del río Tambopata perteneciente al Distrito de Putina Punco, b) margen izquierda del río Tambopata perteneciente al distrito de San Juan del Oro, 
Topónimos de la cuenca del río Tambopata (Puno)

c) margen izquierda del río Tambopata perteneciente al distrito de Yanahuaya,

d) margen derecha del río Tambopata perteneciente al Distrito de Putina Punco,

e) margen derecha del río Tambopata en el distrito de San Juan del Oro y f) margen derecha del río tambopata en el distrito de Yanahuaya

\subsubsection{Margen izquierda del río Tambopata perteneciente al Distrito de Putina Punco}

Markham. Puerto que está en la frontera con Madre de Dios, a donde llegan canoas, barcos, los primeros son neumáticos, inflables que salen de san Ignacio en la desembocadura del río Lanza, los segundos como barcos parten de río Arequipa, Rosario. Las personas en su mayoría son castellano hablantes, un poco de quechuas, aimaras, nativos de la Selva.

Astillero. Puerto llamado por otros Artillero. Está cerca al puerto Markham donde preparan barcos de madera, como de plástico, también se dedican vender armamentos como flechas, carabina, fusil. En su mayoría son castellano hablantes, algunos nativos de la Selva.

Larrabure y Correa. Río, es una de las cuencas del Tambopata a veces tiene un caudal en los meses de enero febrero.

Potzoago. Es otra de las cuencas del Tampopata, por el momento no identificamos el nombre, puede ser de una lengua nativa del lugar.

Showiguensi. Es un río que desemboca al río Tambopata. Está en lengua nativa del lugar.

San Miguel. Río que desemboca al río Tambopata. Aquí hay pocos aimaras muy dispersos.

Sheujichana. También pronuncian shuchui $\sim$ sihuchuy

Echainapa. Río, desemboca al río Tambopata, tiene un puente de material noble.

Shenahuaya. Río que desemboca al río Tambopata.

Padre Zubieta. Río que desemboca al río Tambopata.

Coronel Fernández. Río, desemboca al rio Tambopata, nos informan que antes había aimaras migrantes de Huancané, sus parcelas están abandonadas.

Ministério Ego Aguirre. Río que desemboca al rio Tambopata.

Seco. Puerto es un espacio muy antiguo en la orilla del río Tambopata. Hasta aquí llegaron Villalta (1902), Carbajal (1902), Stiglish (1902) y el Camino de la «Compañía Gomera Forga» (1904). Hay épocas de mayor caudal donde las 
«cachuelas» desaparecen solo aparecen gigantescos árboles en el suelo como barcos en reposo unidos por pastos.

Seco. Río, los aimaras en el lugar llaman siku sikhu, esto nos hace pensar que en realidad no fue castellano «seco» sino siktu de sikuya que es paja brava que están en las orillas del río, pues no hay indicios del río sin agua, es agua remontable como dicen los lugareños que cuentan leyendas guerreras entre arahuacos y aimaras, los primeros bárbaros, los segundos conquistadores que construyen terraplenes, zanjas defensivas y campos drenados por cultivos agrícolas en las lomas artificiales.

Entonces hay la presencia aimara en esos trabajos de grandes cultivos agrícolas, los pastos que llaman siku en las zanjas artificiales son como depósito de fertilizantes que generan calcio, fósforo, potasio mezclados con plantas acuáticas y peces antiguos caracoles, mediante el procedimiento del control de nivel de aguas. Lamentablemente ningún organismo presta atención a este tipo de industria prehistórica aimara amantes de la agricultura, cuando otros sólo se dedican a la extracción de oro, petróleo, madera, plantas industriales, árboles preciosos de ricas resinas.

El indio que no conoció la escuela, con manos encallecidas por el trabajo, por la tierra tiene conciencia de a libertad, tal vez antes era esclavo, perseguido, conjura de la justicia social no quiero decir de los motines de Huancho Lima, la Guerra del Chaco, porque queremos dejar en Paz a ese indio rebelde y progresista.

Vacamayo. Río, desemboca en el río Tambopata es diferente del río Huacamayo que desemboca en el río Inambari. Según Guevara sería el río Távara nombre del jefe de expedición que murió el o3 de junio de 1902.

Vacamayo. Tambo, está en la orilla del río Tambopata, evoca los antiguos tambos donde los viajeros pasaban la noche contando innumerables cuentos pasajes de la vida, etc., la carretera, como la navegación ha hecho que la función de tambos en aimara «tampu» ya no estén vigentes pero quedan los recuerdos de estos espacios de hospedaje.

Todos Santos. Río que desemboca en el río Tambopata. Los aimaras pronuncian «turu santu» como un sustrato o aimarización Tambopata, San Carlos. Tambo, está a la orilla izquierda del río, por el lado derecho de éste río desemboca el río San Carlos. Este nombre es en honor a la finca antigua de Carlos que recogía y plantaba el árbol de cascarilla, goma hasta 1930.

Marte. Pronunciada por aimaras como Marti. Allí estaba antes la finca Martí, Huada. 
Asunto. Río, desemboca en el río Tambopata. En ciertas épocas del año es un riachuelo.

Parrotes. Río, desemboca en el río Tampobata, generalmente se nota la presencia de ingleses en la zona.

Rosario. Río, desemboca en el río Tambopata. También cerca está el río Rosario chico donde el río Tambopata es más ancho y profundo aquí la navegación es en canoa, troncos armados, barcos pequeños o lanchas es común ver que van hacia el norte.

Arequipa. Río, desemboca en el río Tambopata. Hay presencia de carpas de plástico lejos de las plantaciones de la coca, que en ciertas temporadas no previstos recogen sus carpas desarmables y se van al Sur por el río en gomas inflables hasta San Ignacio de allí a otro destino, preferimos no hablar de estos personajes anónimos sin casa, sin mueble; pero sí con dinero y destino. Los aimaras están en caseríos, en población dispersa dedicadas a los raizales, frutos, café y pesca.

Sabatillo. Río, desemboca en el río Tambopata. Los días sábados hacen sus compras en el paradero y los demás días desaparecen.

Mariposa. Quebrada, está frente al río Tambopata. Como su nombre indica hay mariposas de diversos colores que pasan en los charcos pastizales, algunas dicen que ocasionan enfermedades cutáneas pues ponen su huevo en la piel.

Río Blanco. Desemboca en el río Tambopata. Los espacios cercanos a esta cuenca pueden llamarse Blanco como ocurre en el centro Alto Tambopata. El nombre se debe al color cristalino del agua.

Piedad. Quebrada, está en la margen izquierda del río Tambopata. El lugar es muy accidentado pero guarda una riqueza en la variedad de la tierra y plantas, flores, es muy reservado parece que no hay personas.

Intipampa. Río, desemboca en el río Tambopata. En esta parte ya se ve personas que trabajan para el estado como guarda parque, lamentablemente por aquí pasa la frontera del Parque Nacional del Baguaga - Sonene llamado por los aimaras «yalu» trampa, decadencia, como sabemos esta aparente reserva que no deja progresar a los peruanos, a los indios aimaras pobres olvidados, hace progresar a los extranjeros ya sea brasileños, bolivianos, expediciones que estudian la fauna, la botánica en beneficio de grandes empresas extranjeras, cuyos resultados no conocemos.

Quita Calzón. Quebrada, está en la margen izquierdo del río Tambopata cerca al parque Baguaga - Sonene. Seguramente el nombre es por el control de guarda parques que abarcaba a este sitio, ahora no hay control. 


\section{Felipe Huayhua Pari}

Victoria. Está frente a San Rafael de Bolivia presente las siguientes categorías: Centro poblado, donde podemos ver aimaras dedicados al cultivo de coca, café y frutales y los quechuas en menor cantidad dispersos. Río Victoria desemboca en el río Tambopata.

Carranza. Laguna está entre Victoria y Rosada es muy variado los colores que presenta debido al color de las plantas, flores, acuden muchos animales para beber.

Rosada. Frente a la laguna Carranza presenta como categoría sector Rosada con una población considerada y unida.

Ramossani. Está después de Rosada presente categoría del sector poblado. Algunos atribuyen que allí estaban antes los quechuas de Sandia y pusieron el nombre de Ramos debido a que hay una palmera con ese nombre. Los aimaras consideran que fue poblado por ellos por eso el nombre ramos + ni 'que tiene ramos'.

Orgánico. Está frente al río Tambopata.

Flor de oro. Está frente al río Tambopata.

Porvenir. Está en la orilla del río Tambopata, presenta como categoría sector o población dispersa.

Arco punco. Este lugar presenta como centro poblado y sector, luego Centro Arco punco en versión aimara es «Puerta de arco» arku punku. Hay aimaras residentes fijos, golondrinas la primera se dedican a la agricultura, café, frutales, los segundos a la coca, café dejan su casa por temporadas. Otra categoría es Alto Arco Punco que es un centro poblado en la parte alta.

San Fermín. Está más adentro de Azata en la márgen izquierda y derecha del río Tambopata, presenta las siguientes categorías: Centro Poblado de San Fermín conocido como Alto Valle. Puerto San Fermín que está a orillas del río Tambopata, en el lado boliviano también hay puerto. Laguna de San Fermín muy hermosa de color azul. Río San Fermín desemboca en el río Tambopata es caudaloso, como las anteriores pertenece al distrito de Putina Punco.

Azata. De aimara jasa + at'a $>$ jasaat’a región suave castellanizado como azata asaata. La tierra es suave abonado. Comprende las categorías de: Río Azata que desemboca al río Tambopata. Cerro Azata otros llaman Monte Sinaí. Alto Azata, llamado también asaata pata jasaat'a. Bajo Azata o Azata que abarca hasta el río Tambopata. Centro Azata es poblado, la parte media del río Azata. Playa Azata o Asaata pampa, que está en la desembocadura el río Tambopata aquí se juntan ambos ríos, Azata y Tambopata por allí pasan canoas que van al norte llevando compras de arroz, azúcar, fósforo y otros.

$170 \quad$ Lengua y Sociedad 
Topónimos de la cuenca del río Tambopata (Puno)

Monte Sinai. Está al frente del río Azata otros llaman salvavida es un centro poblado donde se dedican al cultivo de café, frutas, raizales, otros, sólo se dedican a la coca y su venta, pues ellos consumen del mercado de Curva Alegre. Muchos jóvenes fueron absorbidos por estos golondrinos en la preparación de pasta durante la noche en los ríos inaccesibles; pero el control de este elemento es frecuente.

Puente de «Compañía Gomera Sandia». Está más adentro de Pampa Grande que en los años de 1902 - 30 usaban para cruzar el río Tambopata. Ahora los aimaras residentes llaman «chaka pampa = puente largo». Más arriba se ha hecho un puente de fiero para ir a Palmerani; en épocas de poca agua los carros, como micros, camionetas cruzan el río sin necesidad de puente. Está al frente de San Rafael de los bolivianos.

Pampa Grande: De aimara y castellano. Pampa + grande = planicie grande, pronunciado por lo aimaras como «Pamparanti». Comprende las siguientes categorías: centro poblado de Pampa Grande y riachuelo de Pampa Grande. Es una zona muy riesgosa presenta manantiales, riachuelos, remansos cultivan arroz, café, coca, alimentos necesarios.

Muerto. Río, desemboca al río Tambopata en ciertas épocas no tiene agua; pero causa derrumbes. Los habitantes dicen que por allí pasaba el camino de la compañía gomera que ellos limpiaron el camino 'remontado' hasta paujil, encontraron en 1940 sacos de cascarilla, goma que por la decadencia de estos productos dejaron en el lugar abandonados.

Los claveles. Es un centro poblado que está lejos del río Tambopata.

Sanupata. Es población dispersa, los aimaras pusieron este nombre por la existencia de la planta llamada sanu.

Paujil. Se encuentra frente a Pampas de Moho, Chunchosmayo en la margen izquierda del río Tambopata, el nombre es honor a la existencia del ave paujil, que los aimaras residentes pronuncian «pawji». Presenta las siguientes categorías: Río Paujil, que desemboca al río Tambopata, Alto Paujil o Alto Pawji o Pawji pata es centro poblado mayoría son aimaras que tienen sus casas cercanas y una población dispersa de quechua. Paujil playa o pawji playa es centro poblado. Paujil pampa o pampa pawji es centro poblado está lejos del río Tambopata. Paujil puju o pawji phuju = manantial de paujil presenta riachuelos que llegan al río Paujil.

Paradero de bolivianos. Está más abajo de Silla Cunca, por allí desembarcan los bolivianos que están al frente, van a Curva Alegre para hacer sus compras. 
Silla cunca . Del aimara silla $=$ hundido, kunka $=$ cuello, nuca $>$ cuello hundido, este lugar presenta una salida en forma de cuello hundido, está más abajo de la desembocadura del río Lanza que es frontera entre Perú y Bolivia.

Arco punco. Del aimara Arku $=$ arco, flecha + punku $=$ puerta $>$ puerta en forma de arco es otro lugar que está más abajo del río Chaquimayo presente piñón de piedra inclinado en ambos lados. Presente las siguientes categorías: Río Arco Punco que desemboca al río Tambopata. Alto Arco punco es centro poblado. Centro Arco Punco es centro poblado que está entre la parte alta y baja del río Arco Punco. Rincón Arco Punco está en la parte alta.

Misquimayo. De quechua misk'i $=$ dulce + mayu $=$ río $>$ río dulce, presenta centro poblado, hay quechuas en esta zona, un riachuelo con este nombre.

Chaqui mayo. De quechua chaki $=$ seco + mayu $=$ río $>$ rio seco, es un sector con riachuelo en la parte alta presenta una laguna de diferentes colores, tiene encanto, hace desaparecer animales.

Lagunitas. Presenta un riachuelo con este nombre en otras épocas inundaba la zona llevándole casas, chacras, presenta el sector de la Laguna Pata con población dispersa de quechuas y aimaras.

San Ignacio. Está al frente de la desembocadura del río Lanza, los aimaras pronuncian como 'sanijnassyu'. Presenta las siguienres categorías: Alto San Ignacio o Sanijnasyu pata, allí está un pequeño aeropuerto que antes vivía un gringo con su familia y peones dedicados al cultivo de cacao, arroz, coca, en ciertas temporadas aterrizaba un helicóptero para echar de menos, seguramente de Bolivia, ahora los hijos de los peones tienen carros de transporte y otras dedicaciones, pero atrás quedaron los recuerdos. Río San Ignacio que desemboca al río Tambopata. Frente a San Ignacio inicia la navegación en neumáticos hacia el norte.

Curva Alegre. Está en el $\mathrm{km} 285$ de Juliaca es un centro poblado muy numeroso en el paradero hay tiendas, restaurantes, hostales, acopio de café, coca y frutas, por eso uno de los informantes aimaras decía «Quisiéramos que sea distrito Curva Alegre, las autoridades de Sandia un poco nos odia, nos margina, necesitamos distritalización, hay más población, negocio, alcalde menor, regidor, colegio, primaria inicial...». Los aimaras pronuncian como «kurwalijri» está vigente la fuerza el vigor del aimara la sociabilidad que se formó en este pueblo hay gentes ilustrados que en tertulias discuten planes alentadoras, literarios, que convertirán a las collas en maestros en las diferentes doctrinas conocimientos y avatares aunque ciertos sectores convierten en ostracismo y apatía a este pueblo. 
Topónimos de la cuenca del río Tambopata (Puno)

Palli phuju. Es centro poblado, antes cuando no pasaba la carretera era zona de descanso tenía tambo para pasar la noche ahora el carro pasa directo ya ni se nota el paradero, puede colapsar.

Tinri phawchinta. Es centro poblado viene de castellano y aimara tigre + phawchinta $=$ cascada $>$ cascada de tigre, cuentan los habitantes que antes por ahí pasaba un camino de herradura y era frecuente ver en esa cascada a los tigres bañándose o tomando agua, igual al palli phuju la población se ha retirado de la zona hacia más adentro como pampa grande, azata, los jóvenes ya no tienen referencia de estos lugares, solo los ancianos, personas de mayor edad se acuerdan de este lugar, antes la población tenía vida independiente que no perjudicaba el uno al otro, el proceso evolutivo como los cambios de actitud han hecho que la gente no sean estacionarios ni sedentarios.

Chocal. Está frente a la desembocadura del río chunchusmayo, presente las siguientes categorías: Riachuelo chocal. Alto chocal es centro poblado. Sector chocal es la parte media del río. Bajo chocal, está cerca el río Tambopata. Es de aimara chhuqha $=$ ave lacustre.

Huayruruni. Es centro poblado, algunas partes como sector antes era chacra de café, frutales ahora parece abandonado o tal vez está en reposo como los aimaras usan el sistema de «aynuqa» un sistema rotativo de cultivos.

Nacaria. Está en el km 276 más abajo de Huinchusmayo. El nombre varía como: Nacaría Nagaria Nakarya. Es centro poblado.

Huinchusmayo. Tambo, de quechua winchus + mayu = río. Antiguo hospedaje de los viajeros, hoy ha quedado abandonado, con una población muy dispersa.

Chunchusmayo . De quechua chunchus $=$ salvaje + mayu $=$ río $>$ río de salvajes o chunchos, este nombre se presenta en la margen izquierda y derecha del río Tambopata como en la parte alta del río Azata por donde pasaba el «camino forga» para trasladar cascarilla, goma hacia puerto seco o hacia Azángaro, presenta las siguientes categorías: Paradero Chunchusmayo donde hay casas de adobe, maderas, pequeñas tiendas. Río Chunchusmayo donde hay casas de adobe, maderas, pequeñas tiendas. Río Chunchusmayo que desemboca en el río Tambopata, tiene un recorrido muy grande desde la parte alta de Azata.

Queullacota. De aimara qiwlla $=$ ave lacustre + quta = laguna $>$ laguna de ave, se ha vuelto un sector abandonado, los cultivos de café naranja están sin deshierbar como monte sin rozar. La laguna con remanzo tiene tortugas, peces, aves, acuáticas. 


\section{Felipe Huayhua Pari}

Tunqui. De quechua tunki = gallito de las rocas. Presenta las siguientes categorías: tunkini en sufijo aimara - ni, que tiene tunki es centro poblado, uno está en el km 252 en las partes altas de Yanamayo el otro cerca a Putina Punco. Río Tunquimayo, desemboca al río Tambopata. Tunquimayo es centro poblado está en la parte central del mismo río. Alto tunquimayo es centro poblado está en la parte central del mismo río. Alto tunquimayo es centro poblado queda en la parte baja cerca al río Tambopata. Tunquipata es centro poblado está a la altura de Alto tunquimayo. Tunqui Cruz es centro poblado está cerca a la carretera en el lado sur del río.

Chusipata. De aimara chusi $=$ cama + pata $=$ terraplén, grada $>$ andén de cama, antes había un tambo donde dormían los viajeros. Está frente a Pampas de Moho, tiene una población dispersa entre aimaras y quechuas.

Desaguadero. Está entre Qiwllacota y quebrada Carmen. Presenta las siguientes categorías: Río Desaguadero que desemboca al río Tambopata. Centro Desaguadero es poblado en la parte de loma hacia otro lado. Desaguadero como paradero es sector que está cerca a la carretera.

Quebrada Carmen. Es un caserío aislado que más parece extranjeros que peruanos. Villa Carmen es sector poblado en la parte alta de Putina Punco.

Putina Punco. De aimara Phutiña $=$ caliente y punku $=$ puerta $>$ puerta caliente . Está frente a la desembocadura del río Pablobamba en el km 266 de Juliaca. Es distrito de la provincia de Sandia, fue creado el 13 de mayo de 2005 como San Pedro de Putina Punco con Ley N. ${ }^{0}$ 28509. Este distrito abarca desde el río Charuyo hasta la frontera con el departamento de Madre de Dios. En 1864 Antonio Raimondi llegó hasta este lugar observó en su barómetro que está sobre 690 mnsm, decía que es una peña viva con puerta, que los cascarilleros pusieron ese nombre. Presenta categoría de Distrito, Centro poblado y otros como: Río Putina Punco que desemboca al río Tambopata. Alto Putina Punco que es otro centro poblado en la ribera del río.

Santo Tomás. Antes era un centro poblado, ahora parece un sector presenta las siguientes categorías: Río Santo Tomás que desemboca al río Tambopata, allí en 1864. A. Raimondi acampó con sus guías. Quebrada Santo Tomás, está más arriba de la carretera tiene poca población. Sector de Santo Tomás comprende a los pobladores de la orilla de este río.

Huayanti. Está al frente de Lacayutine. En aimara es waya = entrada +- nta $=$ Hacia adentro > «entrada o llevar hacia adentro» los aimaras pronuncian como wayanta es caserío de poca población. 
Topónimos de la cuenca del río Tambopata (Puno)

Yabroco. Este sector que más parece abandonado porque los frutales están llenos de malezas, pastos, antes era un centro poblado donde descansaban los caballos, mulas, fleteros, cargadores humanos con cargamento de café que se dirigían hacia yanamayo, San Juan del Oro; ahora atrás quedaron esos recuerdos ya ni más se observa estos muleros, por la penetración de la carretera.

Collpani. De aimara qullpa $=$ salitre $+-\mathrm{ni}=$ que tiene $>$ lugar salitroso. Es sector poblado, presenta el río Collpani que desemboca al río Tambopata.

Huayrurumi. De aimara wayruru $=$ grano bicolor $+-\mathrm{ni}>$ lugar donde produce wayruru. Está frente a San Salvador en el km 260 de Juliaca, presenta el riachuelo Huayruruni que desemboca al río Tambopata y el Centro Poblado de Huayruruni. Hay una población considerable de aimara hablantes, pocos quechuas.

Charuyo. De aimara charu $=$ estrecho, ángulo + uyu $=$ corralón, canchón $>$ corralón estrecho por la forma del lugar. Se encuentra a $265 \mathrm{~km}$ de Juliaca, allí pernoctó A. Raimondi en 1864 conoció con el nombre de pampas. Es centro poblado tiene paradero en la carretera para vender frutas y otras cosas. Río en el límite de los distritos de Putina Punco y San Juan del Oro, es afluente del río Tambopata en la margen izquierda.

\subsubsection{Margen izquierda del río Tambopata perteneciente al distrito de San Juan del Oro}

San Pedro de Casasani. De aimara qasasa $=$ desportillado, roto $+-n i=$ que tiene $>$ lugar en forma de rotura, los aimaras pronuncian como qasasani $\sim$ jasasani $\sim$ q'isasani, es centro poblado está al frente de San Salvador, Santa Ana, está dentro del distrito de San Juan del Oro.

Nueva Esperanza. Presenta sector poblado con paradero en la carretera, riachuelo que sirven para consumo y lavado de café.

Phajchani. De aimara phaxcha $=$ catarata o caída de agua $+-n i=$ que tiene, presenta sector poblado está frente al río Blanco, parece un lugar abandonado debido a que los carros pasan directo antes había tambo para pernoctar la noche.

Ñuñu orco. De aimara ñuñu = ubre + urqu = varón $>$ hombre en forma de Ubre, está a un km de Yanamayo, la carretera abrió el paso la forma geográfica ya es distinto, presenta el cerro de Ñuñu Urco con población dispersa, al lado de Yanamayo es más poblado, hay tiendas, casas nobles de adobe, tapial y cemento. 


\section{Felipe Huayhua Pari}

Yanamayo. De quechua yana $=$ negro + mayu $=$ río $>$ 'río negró, está en el km 252 de Juliaca. Presenta estas categorías: río Yanamayo, desemboca en el río Tambopata frente a Felicidad. Laguna Yanamayo que está en las alturas del río en la cumbre de Nueva Esperanza. Alto Yanamayo, está en la parte arriba del río, allí estaba el antiguo Yanamayo cuando A. Raimondi pasó hacia Putina Punco presenta restos de la población. Rincón de Yanamayo tiene población muy antigua, por allí está una plaza antigua casi en abandono. Centro Poblado de Yanamayo o Centro Yanamayo está en la Carretera que cruza el río Yanamayo, como se puede ver la población ha estado moviéndose desde arriba hacia el río Tambopata. Los habitantes reclaman desde muchos años la distritalización de Yanamayo; pero hoy parece un lugar de paso, pocas veces paran los carros que van a San Juan del Oro o a Sandia. Cuenta Rady Turpo en la Monografía N. ${ }^{\circ} 1$ del Centro Poblado de Yanamayo publicado en el año 2010, que el Señor Limachi de Conima en 1927 a los 7 años ingresa a Chaylluma, luego el Señor Rojtocio Quispe y Toribio Quispe ingresaron en 1938, cuando la carretera aún estaba en Sayto Cota y Sallaco, por el camino de la cabecera del cerro y éstos encontraron personas en las minas de Tunquipata después se dedicaron a la chacra con el tiempo ingresaron más personas.

Cruz Playa. Es centro poblado ya disperso, se dedican a experimentar semillas, de árboles frutales, almácigos, tiene el río llamado Cruz playa. Los aimaras pronuncian como 'rusplaya'.

Nogalani. De castellano nogal y aimara-ni $=$ que tiene $>$ lugar que tiene nogal. Se puede ver a pacchani desde la parte alta, es sector poblado. Presenta las siguientes categorías: río nogalani que desemboca en el río Yanamayo. Cerro Nogalani está frente a Nueva Esperanza. Nogalani pata o parte alta de Nogalani está en la cabecera del riachuelo Nogalani. Hay árboles de nogal por eso el río que atraviesa parece negro como el yanamayo.

Alfonso Ugarte. Se encuentra en la cabecera del río Yanamayo, ocupa sector poblado que pertenece al distrito de San Juan del Oro.

Pajchani. De aimara phaxcha $=$ catarata $+-n i=$ que tiene $>$ lugar que tiene catarata. Es centro poblado, hay aimaras antiguos que residen desde 1940, sus abuelos estaban incluso desde antes, y quechuas que pronuncian como pakcha $\sim$ pakchani. Presenta el río phaxchani que desemboca al río Tampopata.

Tunqui pata. Está en la parte alta del río Yanamayo proviene de dos nombres tunqui $=$ ave + pata $=$ anden. Es sector poblado. 
Topónimos de la cuenca del río Tambopata (Puno)

Quispicanchis. Está en el km 247 abarca tanto el lado izquierdo como derecho del río Tambopata. Es un centro poblado la mayoría son quechua hablantes, Leonardo Quispe construyó la carretilla de madera con freno adecuado para usar en cuestas, barros, el uso se ha propagado en todo Tambopata y en la Sierra. Tiene una mina con el mismo nombre que antes funcionaba ahora está abandonado.

Santa Rosa. Es un centro poblado que está en el distrito de San Juan del Oro, otra como Alto Santa Rosa en el distrito de Yanahuaya.

Challuma. Se encuentra a $244 \mathrm{~km}$ de Juliaca. De aimara challu = obscuro, sucio + uma $=$ agua $>$ challüma, los pobladores pronuncian como chaylluma $\sim$ challu huma o challüma $\sim$ challuma $\sim$ chilluma. Presenta las siguientes categorías: río challuma que desemboca en el río Tampopata. Centro challuma es sector poblado está en la parte media del recorrido del río. Challumapata está en la cabecera del mismo río.

Felicidad. Está en la pampa del río Challuma antes era un centro poblado ahora es sector, la población va menguando tienen actividades diversos desde agricultura hasta manufacturas.

Huaynapata. Esta frente a chuquine en el $\mathrm{km} \mathrm{248,} \mathrm{es} \mathrm{población} \mathrm{dispersa.} \mathrm{En}$ aimara wayna $=$ joven + pata $=$ anden, alto $>$ parte alta joven. Hay otro centro poblado en la cabecera de San Juan del Oro como centro poblado.

Lagunilla. Es sector con población dispersa está en la parte alta de Huaynapata, presenta el cerro Lagunilla.

Carmen Pata. De Carmen + pata > parte alta de Carmen. Está cerca a silla cunca. Es sector poblado presenta tambo que antes era lugar de reposo para la noche.

Sillacunca. De aimara silla $=$ hundido, hondonada + kunka $=$ cuello $>$ lugar hondo como cuello está en la parte alta de San Juan del Oro cerca Huaynapata, antes presentaba tambos para pasar la noche, por allí pasaba camino hacia la quebrada de Tambopata.

San Juan del oro. Pronunciada en aimara como sajwana. Es distrito de la Provincia de Sandia, Raimondi en 1864 solo menciona a San Juan del Oro como antiguos lavaderos de oro en ese tiempo colapsó el lugar y se pregunta San Juan Pata daría el nombre. Calizaya en 2006 en su «monografía de Alto Tambopata» dice que en 1549 los españoles prófugos se retiraron a la región montañosa y fundaron una población en Lavadero de Oro de San Juan del Oro, la decadencia de las minas de San Juan del Oro ocasionó el abandono del lugar; pero posteriormente nuevamente recupera su lugar por la cascarilla, quina, goma, 
coca, café fue fundado en 1944 y creado como distrito el o7 de noviembre de 1955 con Ley N. ${ }^{\circ}$ 12415. El año 1969 que llegamos al lugar muchos tampopatiños tenían su casa, el año 2012 que llegamos encontramos abandonado, muchas cosas rajadas de calaminas oxidadas porque el carro ya no para allí prosigue su viaje hacia Norte.

Belén. Llamado también como wilinpata $\sim$ wilina $\sim$ centro poblado que pertenece a San Juan del Oro.

\subsubsection{Margen izquierda del río Tambopata perteneciente al distrito de Yanahuaya}

Llami Llami. Está en la frontera de los distritos San Juan del oro y Yanahuaya. De aimara llami - = palpar. Posiblemente dieron este nombre porque este lugar se camina a gatas de cuatro pies porque es muy resbaloso. Presenta las categorías de: río Llami Llami que es frontera que separa ambos distritos desembocando en el río Tambopata. Centro poblado de Llami Llami está en el distrito de Yanahuaya. Quebrada de Llami Llami recorre toda la parte baja delrío, por aquí acampó A. Raimondi en su viaje a Putina Punco.

Carapata. De aimara q'ara $=$ pelado + pata $=$ andén $>$ andén alto pelado, algunos pronuncian como karapati recordando que antes en época de Tambos estos estaban plagados de piojos, ahora es sector casi abandonado.

Muyuhuasi. De quechua y aimara muyu y quechua wasi $=$ casa $>$ casa redonda. Es centro poblado de San José de Muyuhuasi en su mayoría son quechuas y pocos aimaras.

Tambopata. De aimara tampu = posada, albergue, alojamiento + pata = andén, terraplén, andén de posada o descanso. Villalta, en 1902, recorrió del Callao (Lima) a Puerto Seco en el río Tambopata, de Pucará a Sandia por el camino Forga, viaja a pie, igual de Sandia a Puerto seco a pie, en este último recorrido desde el Tambo Cahuanchaca hasta Tambo de Casa-Forga cerca a Puerto Seco, cita alrededor de 10 tambos donde pernoctaron las noches, así como: Cahuanchaca, Ichubamba, Cachicachi, Vallegrande, Chunchosmayo, La Cumbre, Rosario, San Carlos, Krüger y Casa Forga. A. Raimondi en 1864 en su recorrido llega a San Juan Pata y después cuando regresa la llama Tambopata, encuentra y casi abandonado. Los que viajaron a pie de Conima a la montaña como Alberto Choquechambi en 1940 y Escolástico Huayhua en 1950 se acuerdan haber dormido en casuchas de madera llamando tampu 
Topónimos de la cuenca del río Tambopata (Puno)

y el día siguiente dirigirse desde temprano a otro tampu para dormir, así en la Selva menciona como 4 a 5 tampus, de las alturas llegaban en 6 a 7 días. Este nombre tan antiguo, como el hombre de San Juan Pata ha quedado reducido a Tambopata o San Juan del Oro. Ahora tanto el río Tambopata como el río Inambari son subhoyas o subsistemas hidrográficas del río Madre de Dios, los dos son como dos arterias que riegan el Departamento de Puno y sobre éstas cuencas de largo recorrido tanto quechuas y aimaras están asentados como dos pulmones (derecha e izquierda) que en verdad han solucionado la pobreza, desocupación, hambre, subdesarrollo de los andinos abandonados a su suerte, Martínez decía «ombligo de la primera colonización indígena». El río Tambopata para Raimondi y Luna nace del nevado de Palomani Grande en la frontera con Bolivia, y para Calisaya nace del nevado de Salluyo (Bolivia) con el nombre de Chicaillane, para Guevara es río queñuani que, para Tejada nace de Sina, desciende hacia el norte en pleno territorio peruano pasando el distrito de Yanahuaya, San Juan del Oro y Putina Punco, de la desembocadura del río Lanza a la desembocadura del río San Carlos es el límite de los países Perú y Bolivia ofreciendo grandes posibilidades para la navegación, desde San Carlos al Sur de río Colorado, penetra a $120^{\circ}$ hacia el norte pasando Puerto Seco, Puerto Markam en la frontera con el departamento de Madre de Dios y finalmente desemboca al río Madre de Dios en Puerto Maldonado. En su recorrido recibe en la margen izquierda 47 ríos ( 34 en el distrito de Putina Punco, 6 en el distrito de S. J. O. y 7 en el distrito de Yanahuaya). En la margen derecha recibe 13 ríos (8 en el distrito de Putina Punco, 2 en el distrito S. J. O. y 3 en el distrito de Yanahuaya), en total son 60 ríos afluentes de este majestuoso río Tambopata. En la orilla de estos y otros ríos y espacios más, principalmente, primero se asentaron como tampus que algunos llaman colonización, migración y conquista, luego convirtieron en caserío, sector, centro poblado, distrito y provincia en ese orden. Según el clima, el espacio, usan el piso ecológico así categorizan en alto, bajo, centro, sector, rincón, cerro, quebrada, paradero, primera sección, segunda sección, tercera sección, etc. y no sólo eso, ahí está presente el dinamismo económico las clases sociales, familias contradictorias entre quechuas y aimaras, las grandes familias campesinas, y ladinos paralelo al río está el camino de herradura "Gomera Sandia» la carretera que ya llega a Victoria por el lado derecho solo la Herradura. Está presente en este espacio la aplicación de los saberes andinos, la reciprocidad, redistribución, colectivismo y faccionalismo, aquí no cabe ni la utopía del indianismo donde 


\section{Felipe Huayhua Pari}

el indio es la salvación, ni la idea del comunismo donde el proletariado es la salvación, sino aquí está presente el mejoramiento de las condiciones de vida de los habitantes, como decía Luna «... debemos recurrir en asuntos de investigación histórica de la región que habita, sólo queda en él, un recuerdo vago de ciudades destruidas todavía palpitantes a su llegada, de las que ignoró siempre el origen de su construcción. La vida humana había desaparecido de ellas las gentes huidas a diferentes regiones: a los altos andes, a las selvas, a los desiertos del Sur, no regresaron a intentar la reacción ni la reconstrucción de su cultura» (Luna, 1968, p. 17).

La cuenca de Tambopata lleva otros nombres conforme que van llegando los habitantes: San Juan del Oro (1549) por los prófugos de Pizarro, Baguaja (Huarayos), Apiroa (iñaparis), Huacani (aimaras, mashcos) Corihuayco (aimaras), Ambaya o Dorado (españoles) Aynacha (aimaras), Quebrada de Tambopata (Raimondi) Villa Yunga (ladinos, abuelos), montaña valle (ladinos), Alto Tambopata (modernamente).

Presenta el centro poblado con el nombre de San Martín de Tambopata que está en el distrito de Yanahuaya al Sur de Muyuhuasi. EL Parque Nacional de Bahuaja sonene está a la altura del río Colorado.

Quiquira. Está en la parte extrema del distrito de Yanahuaya. Es centro poblado con el nombre San Lorenzo de Quiquira o Alto Quiquira, los aimaristas como llaman en el lugar, conocen como lakani = 'que tiene borde'. Bajo San Lorenzo que es sector más bajo posiblemente es la continuación. En 1864 A. Raimondi pasó por este lugar llamaba 'laccani, quiquira, San Lorenzo'.

Jahuanaco. Es población dispersa, presenta el río Jahuanaco que desemboca en el río Huarihuari.

Huari Huari. Río del mismo nombre es frontera entre Yanamayo y Sandia.

Moruncunca. Cerro del mismo nombre varía como murunani $\sim$ murunikunka. De aimara muru $=$ sin cabeza, mocho $-\mathrm{ni}=$ que tiene + kunka $=$ cuello $>$ «cuello sin cabeza». Antes era sector poblado con tambos para dormir de noche, por la penetración de la carretera, es solo de pasada.

Sicuni. De aimara siku $=$ paja brava +- ni $=$ que tiene $>$ lugar con paja brava, también se llama warmi marka = 'pueblo de mujeres'. Es centro poblado.

Caballuni. De castellano + aimara $-\mathrm{ni}=$ que tiene $>$ lugar que tiene caballos, es centro poblado.

Cruzpata: De castellano, aimara Cruz + pata $=$ andén con cruz. Es centro poblado cerca a Yanahuaya en el $\mathrm{km} 238$. 
Topónimos de la cuenca del río Tambopata (Puno)

Yanahuaya. De quechua yana $=$ negro y aimara waya $=$ parte o región. Está a 238 $\mathrm{km}$ de Juliaca. Es distrito de Sandia que se formalizó el 23 de abril de 1962 con Ley N. ${ }^{\circ} 14062$ y así se separó del distrito de San Juan del Oro.

La Cumbre. Es tambo andino que está en abandono.

Yanacocha. De quechua yana $=$ negro + qucha $=$ laguna $>$ laguna negro. Está en el km 217 de Juliaca. Es centro poblado del distrito de Yanahuaya.

Calzada. Río con ese nombre, muy barroso los viajeros a pie cruzaban tendiendo palmeras, pajas por el camino. Está en el km 217 de Juliaca es centro poblado.

Huañaraya. De aimara waña $=$ seco + raya $=$ región, parte $>$ región seca. Es centro poblado está más debajo de río calzada.

Locaria. Río del mismo nombre desemboca en el río Tambopata.

Cota huaña. Del aimara quta $=$ lago + waña $=$ seco $>$ 'lago secado', es centro poblado de Yanahuaya.

Purumpata. De aimara puruma $=$ tierra estéril + pata $=$ anden $>$ andén en tierra fértil. Es centro poblado de Yanahuaya.

Jahuanchaca. De aimara qhawaña $=$ vigilar + chaka $=$ puente, cerro $>$ cerro o puente donde se vigila.

Ichubamba. De aimara jichhu $=$ paja + pampa $=$ planicie $>$ planicie de ichu.

Lulimachay. Es sector de Yanamayo.

Maravillas. Es centro poblado de Yanacocha.

San Martín. Río del mismo nombre desemboca al río Tambopata

Huichulluni. Río del mismo nombre, de aimara wichhullu $\sim$ chhuchhullu $=$ hueso + -ni 'que tiene huesos'

Chullo. Cerro, de aimara ch'ullu = gorro, encargar.

Huacapata. De aimara wak’a $=$ lugar sagrado + pata $=$ anden $>$ andén sagrado, también llamado Peñón de oro, es cerro en la frontera con Sandia.

\subsubsection{Margen derecha del río Tambopata perteneciente al Distrito de Putina Punco}

Morro. De aimara muru = truncado, mochado. Es una lomada que está cerca a Madre de Dios.

Heath. Del inglés Edwin R. Heath de Wisconsin (1839 - 1904). Es río con el mismo nombre que nace del Sudeste de la provincia boliviana Iturralde recorre por la frontera entre Perú y Bolivia hasta desembocar en el río Madre de Dios. Está el Puerto Heath muy concurrida por canoas, barcos. Pampas de Heath, lugar 
dentro del Parque Nacional Baguaga - Sonene muy plano donde cultivan arroz, cacao, castaño, frutillas en gran cantidad, hace poco muchos aimaras llegaron a este parraje; pero la creación del Parque Nacional restringe sus trabajos, así queda la idea, ¿Progreso o Reserva?. Los aimaras llaman awuyama o awyama, los selváticos lo llaman sonene.

Matehue. Este río desemboca al río Tambopata, presenta la quebrada, cerca al Rodadero.

Forga. Campamento Forga y fincas antiguas de Forga que se dedicaban hasta 1940 en extracción de cascarilla.

Marte. Campamento Martí - Huada de los años 1902 - 1930, antes estaba las fincas de tal compañía pero por la decadencia de cascarilla y frecuentes asaltos de parte de los salvajes fueron abandonando. Presenta la Quebrada Marte, antiguo Martí, el centro o sector Marte hay habitantes que se dedican al cultivo de raíces de consumo y frutas.

Cajones. Río Cajones, cuentan que antes cuando encontraban oro depositaban en cajones que era como unidad de medida, que pasaban cada uno un quintal.

Boquitas. Río Boquitas o Boquillas desemboca al río Tambopata frente al río Blanco.

Todos Santos. Es sector frente al río vacamayo está en la parte izquierda y derecha del río Tambopata abarca hasta San Carlos.

San Carlos. Río San Carlos, también estaban antes las fincas antiguas de Carlos, Huada y Martí ahora ya son olvidadas, con nuevos pobladores.

Baguaga - Sonene. Parque Nacional con este nombre la frontera pasa más adentro de la quebrada Quita Calzón, San Carlos, frente al río Colorado de Bolivia la denominación es al río Tambopata y el río Heath.

Colorado. Río con ese nombre llamado por los habitantes como yalu = sosiego. Desde allí el río Tambopata se interna hacia Puno y Madre de Dios a $120^{\circ}$ grados, el río es más caudaloso y navegable en canoas, barcos de color rojo por la tierra.

San Rafael. Río con ese nombre que desemboca al Tambopata frente a Paujil playa, pertenece a Bolivia, presenta Rodadero San Rafael.

Urubamba. De aimara uru = día y pampa = planicie $>$ planicie claro como día . Presenta categorías como: San Lorenzo de Urubamba sector disperso de caseríos. Río Urubamba, desemboca en el río Tambopata frente a Misquimayo. Centro Urubamba sector poblado está en el distrito de Putina Punco. Alto Urubamba frente a Putina Punco está en la orilla del río Urubamba. 
Topónimos de la cuenca del río Tambopata (Puno)

Palmerani. De castellano palmera y aimara $-\mathrm{ni}=\mathrm{con}>$ lugar que tiene palmera. Está frente el río Lanza, presenta un riachuelo y centro poblado llamado San Lorenzo de Palmerani, más al Sur está otro centro poblado San Román de Palmerani allí es frecuente las peleas con los quechuas por la frontera de sus terrenos cuentan que han ocasionado muertes estas riñas de discriminación lingüística.

San Pedro. Es centro poblado, está frente a Santo Tomás.

Janansaya. Es centro poblado, está al Sur de San Pedro.

Pampa Gloria. Es centro poblado, está al sur de Palmerani.

Río San Felipe. Desemboca al río Tambopata frente a Arco Punco.

Chunchusmayo. Está al sur de Nacaria, presenta las siguientes categorías: río Chunchusmayo desemboca al río Tambopata. Centro poblado de Chunchusmayo está en las orillas de este río. Chunchusmayo. Cerro Chunchusmayo. Rincón de Chunchusmayo.

Moho. De aimara muju = semilla, en honor al distrito de San Pedro de Moho de Huancané, ahora ya es provincia. Presenta Pampas de Moho un centro poblado procedentes de la provincia aimara de Moho. Está frente a Chocal.

Alto Valle. Sector disperso, presente cultivos de café, plátano, coca.

Salinas. Centro poblado Pampa Salinas, posiblemente se debe a los aimaras procedentes de Rosaspata - Huancané, el lugar es amplia región.

Dulce. Río con este nombre está en la frontera con Bolivia, desemboca el río Lanza.

Lanza. Está frente a Paujil Playa y San Ignacio. Presentan estas categorías: río Lanza que nace de los nevados de Bolivia, es frontera entre Bolivia y Perú y desemboca al río Tambopata frente a San Ignacio de aquí el río es más ancho permite la navegación al norte en pequeñas embarcaciones como llantas, gomas inflables. Centro poblado Miraflores Lanza. Lanza Miraflores está al norte del río Dulce a la altura de Tunqui Cruz. Centro Lanza está frente a San Román es centro poblado donde hay trabajos tradicionales. Alto lanza esta por el río Dulce. Lanza segunda Sección está a la altura de Santo Tomás y al sur del Río Dulce. Lanza tercera sección está a la altura del río Nueva Esperanza, al sur de Lanza Segunda Sección, es hasta por los inicios del río Lanza.

Jahuarmayo. Está por el río Dulce hay poca población, los habitantes pronuncian como aimaras jawar mayo, y otros como yawarmayo.

Usumayo. Caserío antiguo en proceso de extinción y renovación, está en los inicios del río Lozabamba. 
San Benigno. Está frente a Tunqui Cruz, presenta el río que desemboca al río Tambopata, Centro San Benigno, es sector poblado en la parte media del río San Benigno. Benigno es centro poblado al Sur de Centro San Benigno, posiblemente correspondía al Alto o parte alta, pero no hay esta referencia.

Santa Fe. Es centro poblado frente a Putina Punco.

Lozabamba. Este río desemboca al río Tambopata frente a Chunchusmayo en sus orillas están Pampas de Moho, Pampa Gloria, pero no han dividido en categorías como Bajo, Alto, Centro como ocurre generalmente con otros ríos.

Pampa Gloria. Está en la zona intermedia del río Lozabamba, es centro poblado.

Florida. Está en la desembocadura del río Pablobamba.

Progreso. Está por el río Pablobamba al Sur de Florida.

Collpani. También hay al lado izquierdo del río Tambopata y al lado derecho.

Huaranca. De aimara waranqa $=$ mil, barranca, está en el río Pablobamba. La pronunciación varía como waranja waranqa. Es centro poblado de diversos pobladores.

Vilcabamba. De aimara wilka $=$ Dios, $s o l+$ pampa $=$ planicie $>$ planicie sagrada. Está al Sur de Huancabamba.

Huancabamba. De aimara wanka $=$ piedra, sol + pampa $=$ planicie $>$ planicie roquedal. Está al sur de Lucine, es centro poblado, el transporte de café y frutas hacia Putina Punco hacen en acémilas, mulas y cargadores como hacían antes, hay camino herradura hacia San Juan del Oro como hacia Putina Punco.

Pablobamba. De Pablo + pampa > planicie de Pablo. Presenta estas categorías en todo el recorrido del río: Río Pablobamba nace del cerro Lurini en la frontera con Bolivia y desemboca en el río Tambopata frente a Putina Punco su recorrido es muy largo, llega a los distritos de Yanahuaya, San Juan del Oro y Putina Punco. Allí están varios centros poblados como: Huaranca, Vilcabamba, Pablobamba, Charubamba, lucine, bajo pablobamba y alto Pablobamba como otros. Centro Pablobamba, es sector poblado a veces llaman Pablobamba, después sigue Santa Cruz de Pablobamba que pertenece al distrito de San Juan del Oro, luego Carmen de Pablobamba también está en el distrito de San Juan del Oro Bajo Pablobamba ya pertenece al distrito de Yanahuaya. Alto Pablobamba está al Sur de Bajo Pablobamba también pertenece al distrito de Yanahuaya, allí están los antiguos aimaras.

Lacayutini. Está a la altura de Felicidad, al Sur de Charubamba es centropoblado. 
Topónimos de la cuenca del río Tambopata (Puno)

Moronani. De aimara Muru $=$ truncado +- ni que tiene $>$ lugar en forma de loma sin punta. Sector poco poblado, pertenece al distrito de Putina Punco detrás de Chuquini y Santa Ana.

\subsubsection{Margen derecha del río Tambopata en el distrito de San Juan del Oro}

San Salvador. Está frente a Huayruruni, es centro poblado.

Santa Ana. Es centro poblado frente a Nueva Esperanza, allí están en su mayoría aimaras de conima que han llegado en 1940, sus hijos ya abandonaron el lugar, algunos vendieron a otros.

Charubamba. De aimara charu = ángulo, estrecho + pampa $=$ planicie $>$ planicie que termina en ángulo o angosto, está en el río Blanco al sur de Lucine. Es centro poblado.

Carmen de Pablobamba. Es citado en Pablobamba.

Santa Cruz de Pablobamba. Es citado en Pablobamba.

Huayrapata. Es zona aimara posiblemente se debe a migrantes de Huayrapata. Huancané, antes estaban en su mayoría aimaras de Conima, Putina, Cojata, HUayrapata ahora ya sus hijos han abandonado, algunos han vendido, otros fueron expropiados por instituciones educativas.

Lucine. Es centro poblado está a la altura de Chuquine o San Salvador, es una zona muy accidentada que están plantaciones de caña, café, naranja en medio de hierbas por el abandono del lugar, en algunas partes hay habitantes que se dedican a la ganadería de ovino, vacuno, cuy, aves.

Chuquini. Es centro poblado disperso, antes era lugar de reposo para los viajeros que iban a Lucine, algunos reconocen como San Salvador.

Zapalluni. Es centro poblado está detrás de Charobamba, presenta el río Zapalluni que desemboca al río Pablobamba.

Uycusmayo. Es centro poblado, presenta el río Uycusmayo que desemboca al río Pablobamba. De quechua uyku $=$ tubérculo + mayu $=$ río $>$ río con uyku.

Tincus playa. De aimara tinku $=$ encuentro $>$ playa de convergencia o encuentro. Es sector dispersa.

Torre Mamani. Es sector poblado, llamado también Torre Alegre.

Blanco. Río que desemboca al río Pablobamba al Sur de Lucine, nace de las alturas de Lusini por la frontera con Bolivia. 
Quispicanchis. Llamado también Quispicancha. De aimara qhispi = salvación + kancha = corralón, canchón, plaza $>$ plaza de Salvación, está frente a Santa Rosa, al Norte de Botijani.

Yurajmayo. De quechua Yuraq = blanco + mayu = río $>$ 'río blanco', es centro poblado que está frente a challuma.

Cerro chunchucahuana. Famoso cerro, de quechua, aimara ch'unch'u = salvaje + qhawaña = vigilar $>$ Vigilancia de chuncho, es como mirador, muy alto, está al frente de S. J. O. se dice que antes los salvajes vigilaban si alguien entra a la montaña, al ver mataban a los ingresantes.

Botijani. Está frente challuma y Felicidad es un cerro en forma de botella, hay pobladores según cuentan pueden ser antiguos residentes.

\subsubsection{Margen derecha del río tambopata en el distrito de Yanahuaya}

Blanco. Río que desemboca al río Pablobamba al Sur de Lucine nace de las alturas de Lusini por la frontera con Bolivia, está dentro del distrito de Yanahuaya.

Santa Cruz. Centro poblado que está a la orilla del río Blanco al norte de Jerusalén.

Jerusalén. Centro poblado del distrito de Yanahuaya en la rivera del río Blanco al norte de San Vicente.

Uycusmayo. De quechua uykus $=$ tubérculo comestible + mayo $=$ río $>$ río con tubérculo. Presenta el río Uycusmayo que desemboca al río Pablabamba, centro poblado, está en el distrito de Yanahuaya.

San Vicente. Está en la quebrada de Pablobamba, pertenece al distrito de Yanahuaya. Es centro poblado que está dispersándose.

Río impuruni. Desemboca al río Pablobamba a la altura de Muyuhuasi, en el distrito de Yanahuaya.

Río zapallomayo. Desemboca por el lado derecho al río Pablobamba al sur de impuruni. En quechua es río de zapallo.

Río cotusmayo. Desemboca por el lado derecho al río Pablobamba al sur de Zapallumayo.

Cerro chirluna. Está ubicado al norte de Yahuarmita en el distrito de Yanahuaya.

Río Pucasucho. Desemboca al río Tambopata al Sur de Yahuarmita. Presenta centro poblado de Pucasucho. 
Topónimos de la cuenca del río Tambopata (Puno)

Yahuarmita. Es centro poblado está en la rivera derecha del río Tambopata al norte de la desembocadura del río Pucasuchu. Varía como Yawarwita = turno de llanto, pertenece al distrito de Yanahuaya, presenta caseríos de lavaderos de oro.

Limpucuni. Es centro poblado del distrito de Yanahuaya está en la desembocadura del río Blas, recibe otro nombre como Huayrapata.

\section{Raqui raqui.}

Blas. Está en el distrito de Yanahuaya, como río Blas desemboca al río Tambopata cerca a Limpucuni.

Pablobamba. En el distrito de Yanahuaya presenta el Bajo Pablobamba, y Alto Pablobamba, incluso como río Alto Pablobamba, citado más arriba.

Tincusplaya. Centro poblado que en aimara significa 'playa de encuentro', hay sector poblado con residentes muy antiguos.

Huacaychuru. De quechua waqhay $=$ llorar + churu $=$ angosto $>$ 'zona angosta donde se llora'

Tocorani. De aimara tuqura $=$ carrizo $+-n i=$ con. Lugar que tiene carrizo.

Pilco. De aimara pillku = sin cola, roma. Es centro poblado de yanahuaya, también conocido como Pilcopata = andén sin cola, antes había categorías espaciales de alto, bajo y centro, ahora solo conocen como Pilco. Está al Sur de Purumpata.

Catarani. De aimara Katari = serpiente $+-n i>$ 'lugar con serpientes', es centro poblado de Yanahuaya se encuentra detrás de Pilco.

Cholunca. Varía la pronunciación como chullunca. Viene de aimara chullu chulluku $=$ salta monte + kunka $=$ cuello $>$ lugar en forma de cuello con saltamontes, es un lugar muy antiguo los residentes aimaras abandonaron, actualmente son nuevos residentes que más hablan castellano. Presenta el cerro con ese nombre.

Aguada. Centro poblado de Yanahuaya, está al Sur de Catarani en la rivera del río Blas.

Huajomayo. Es río que desemboca por la derecha al río Pablobamba cerca al cerro cholunca en el de Yanahuaya - Es castellano y quechua bajo + mayu = 'río bajo'.

San Felipe. Es centro poblado de Yanahuaya, está al frente de Maravillas.

Llami Llami. Es centro poblado al final de Yanahuaya al sur del Alto Pablobamba, el río Llami Llami que es frontera con San Juan del Oro es otro que está a la izquierda del río Tambopata.

Cerro Chacata. Se encuentra en la frontera con Bolivia, es zona de clima muy frígido. Su nombre proviene de chaka = puente, cruz, cerro.

Cerro lurini. Está al Sur del Cerro Chacata por la frontera con Bolivia. 


\section{Patrón tipológico de la denotación}

A continuación, se presenta el análisis lingüístico de los topónimos estudiados.

\subsection{Análisis sobre el nombre de los lugares (sobre la denominación, denotación, topónimos)}

5.1.1. Hay nombres en castellano que alterna con la sintaxis aimara, según el uso de los hablantes ya sean castellanos, aimaras, quechuas, guarayos

$\begin{array}{lcl}\text { versión aimara } & & \text { versión castellana } \\ \text { pauji playa } & \sim & \text { playa pauji } \\ \text { pauji pampa } & \sim & \text { pampa paujil } \\ \text { pauji alto } \sim \text { pawjipata } & \sim & \text { alto paujil } \\ \text { Miraflores lanza } & \sim & \text { lanza Miraflores } \\ \text { Tunqui cruz } & \sim & \text { cruz tunqui } \\ \text { Cruz playa } & \sim & \text { playa cruz } \\ \text { Torre mamani } & \sim & \text { torre alegre } \\ \text { Inti pampa } & \sim & \text { pampainti } \\ \text { Valle pata } & \sim & \text { alto valle } \sim \text { valle futuro } \\ \text { Asata pampa } & \sim & \text { playa asata } \\ \text { Asata pata } & \sim & \text { alto asata } \\ \text { Tinri phawchinta } & & \\ \text { Tunkipata } & & \\ \text { Chusi pata } & & \\ \text { Chunchu qhawaña } & & \\ \text { Tinkus playa } & & \\ \text { Arkopunco } & \end{array}$


Topónimos de la cuenca del río Tambopata (Puno)

\subsubsection{Nombres términos con}

sufijos aimara - ni 'tener'

$\begin{array}{ll} & \text { chuquini } \\ \text { Palmerani } & \text { lusini } \\ \text { Tunquini } & \text { botejani } \\ \text { Huayruruni } & \text { sicuni o warmi marka } \\ \text { Lacayutini } & \text { huatasani } \\ \text { Chicaillani (río en Bolivia) } & \text { Caballuni } \\ \text { Collpani } & \text { moronani } \\ \text { Pacchani } & \text { nogalani } \\ \text { Huichulluni } & \text { lucine } \\ \text { Mamani } & \text { zapalluni } \\ \text { Impiruni } & \text { caballuni } \\ \text { Tocorani } & \text { ramosani } \\ \text { Lurini } & \end{array}$

\subsubsection{Nombres terminados en} pata que alterna con alto

Sanupata

Chusipata

Huayrapata

Huaynapata

Tunquipata

Chucalpata

Betespata

Carmenpata

Tambopata

Ccarapata

Cruz pata

Porompata (recto)

Chillapata

Azatapata alto azata

Huacapata

Laguna pata 


\subsubsection{Nombres duplicados - para especificar} el lugar lo que caracteriza más

Llinqui llinqui

Huari huari

Cuyo cuyo

Llamillami

Raqui raqui

\subsubsection{Nombres que procede de aimara}

Azata asät’a

Pawji phuju

Tinri phawchinta (antes era muy conocida; con la penetración de la carretera están olvidando estos nombres)

Arco punku

Charüyu

Huaranca

Challuhuma

Urubamba

Palli phuju

Sanupata

Sillacunca

Qiullacota

Urubamba

Collpani

Vilcabamba

Huancabamba

Yalu

Intipampa

Chocal

Huayruruni

Huayanti

Phajchani

Tincus playa

Huaynapata

190 Lengua y Sociedad 
Topónimos de la cuenca del río Tambopata (Puno)

\section{Carapata}

Sicuni

Purumpata

Cotaña huaña

Huarcapata

Mamani

Limpucuni

Pilco

Chacata

Ñuñu urco

Huañaraya

Ichubamba

Phuju puju

\subsubsection{Nombres en quechua}

Cocosmayo

Uycusmayo

Misqui mayo

Chaquimayo

Tunqui mayo

Cotusmayo

Chunchus mayo

Huinchusmayo

Janansaya

Yanamayo

Kutus mayo

Pucasucho

Yurajmayu

Quispicanchis

Yahuarmita

Muyuhuasi

Yanahuaya

Lacayuti

Yahuanco

Huacaychuru 
Felipe Huayhua Pari

Yanacocha

Zapallo mayo

Huaychumayo

Uycusmayo

\subsubsection{Nombres terminados en -bamba <-pampa}

Urubamba

Charubamba

Pablobamba

Vilcabamba

Huancabamba

Charabamba

Ichubamba

Lozabamba

Intipampa

Asatapampa

Paujilpampa

\subsubsection{Nombres terminados en -huaya}

Huanahuaya $\sim$ huanaraya

Yanahuaya $\sim$ yanahuara

\subsubsection{Nombres terminados en -cocha, -cota}

Yanacocha

Sayt'ucota

Qiullacota

\subsubsection{Nombre terminado en -saya}

Janansaya 
Topónimos de la cuenca del río Tambopata (Puno)

\subsubsection{1. Área espacial diferenciada}

\section{Tunquini}

Río tunquini tunquimayo aunque ya no presenta su equivalente en aimara 'jawira' Alto tunquimayo $\sim$ tunquimayo $\sim$ pata $\sim$ tunquipata

Bajo tunquimayo

Sector tunquimayo

Azata (CP)

Río azata

Alto azata

Bajo azata

Centro azata

San Fermín (sector) valle futuro

Alto San Fermín Alto Fermín

Puerto San Fermín

Cuartel San Fermín

Río San Fermín

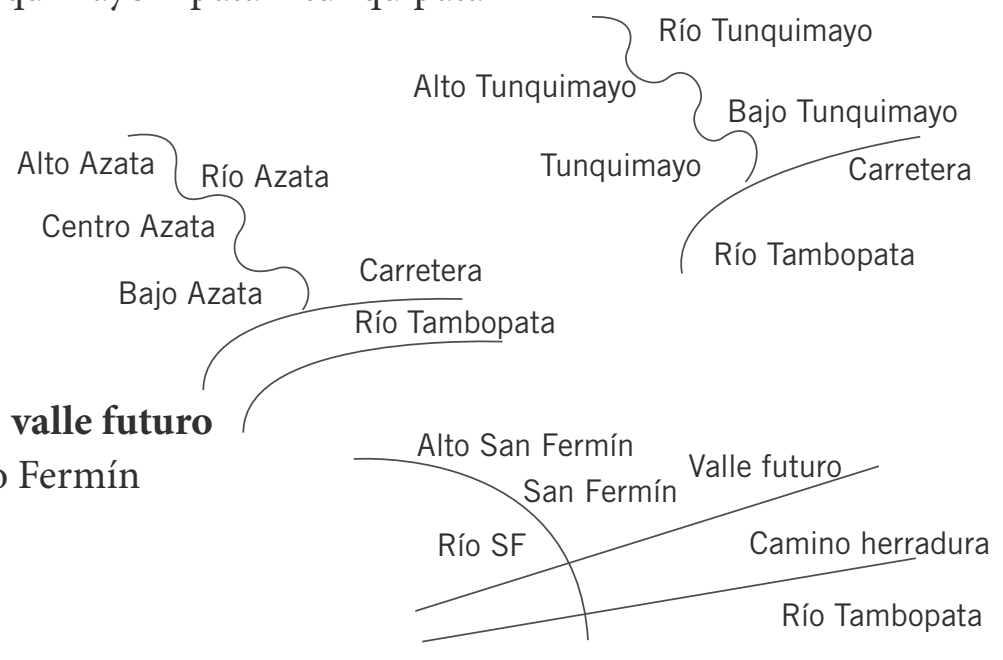

\section{Pablo bamba}

Alto Pablobamba

Bajo Pablobamba

Pablobamba sector o centro

Río Pablobamba

Carmen de Pablobamba (sector)

Santa Cruz de Pablobamba (sector)

Cruz playa

Río Cruz Playa

Tambopata sector

San Martín de Tambopata

Río Tambopata

Alto tambopata

Bajo tambopata

Yanamayo

Río yanamayo

Alto yanamayo o alto selva yanamayo

Bajo yanamayo o sector yanamayo

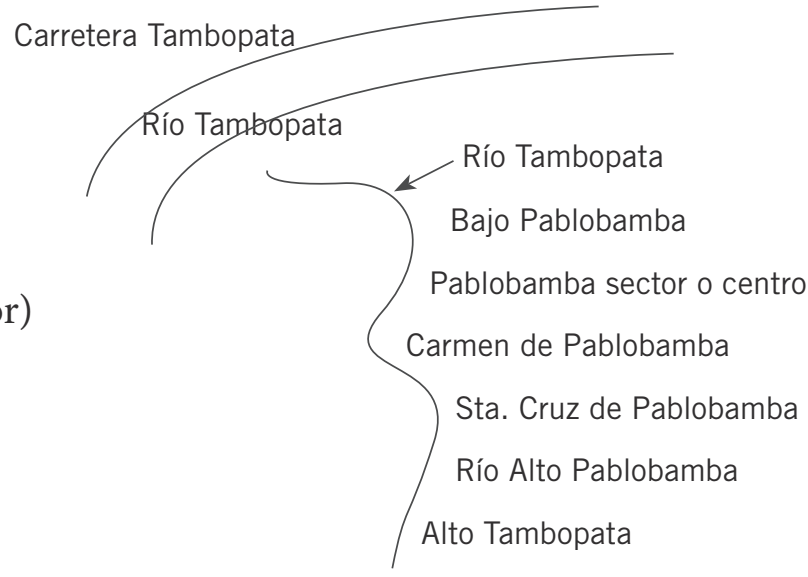

Yanamayo antiguo. 
Felipe Huayhua Pari

Heath

Río Heath

Pampas de Heath

Benigno sector

Río San Benigno

Pampa glorioso

Río Pampa glorioso

Chunchusmayo

Río Chunchusmayo

Colorado

Río Colorado

\section{Lanza}

Lanza primera sección

Lanza segunda sección

Lanza tercera sección

Lanza Miraflores o Miraflores lanza

Río Lanza

Nombres que comienza con pampa

Pampa grande

Pampa gloria o pampa glorioso

Pampas de Moho

Pampa salinas

Pampa de trapiche

Nombres que comienzan con denominación de santos

San Miguel

San Carlos

San Rafael

San Fermín Fermín

San Lorenzo

San Pedro

San Román

San Ignacio

Santa Cruz

San Pedro Casasani

Santo Tomás

San Salvador
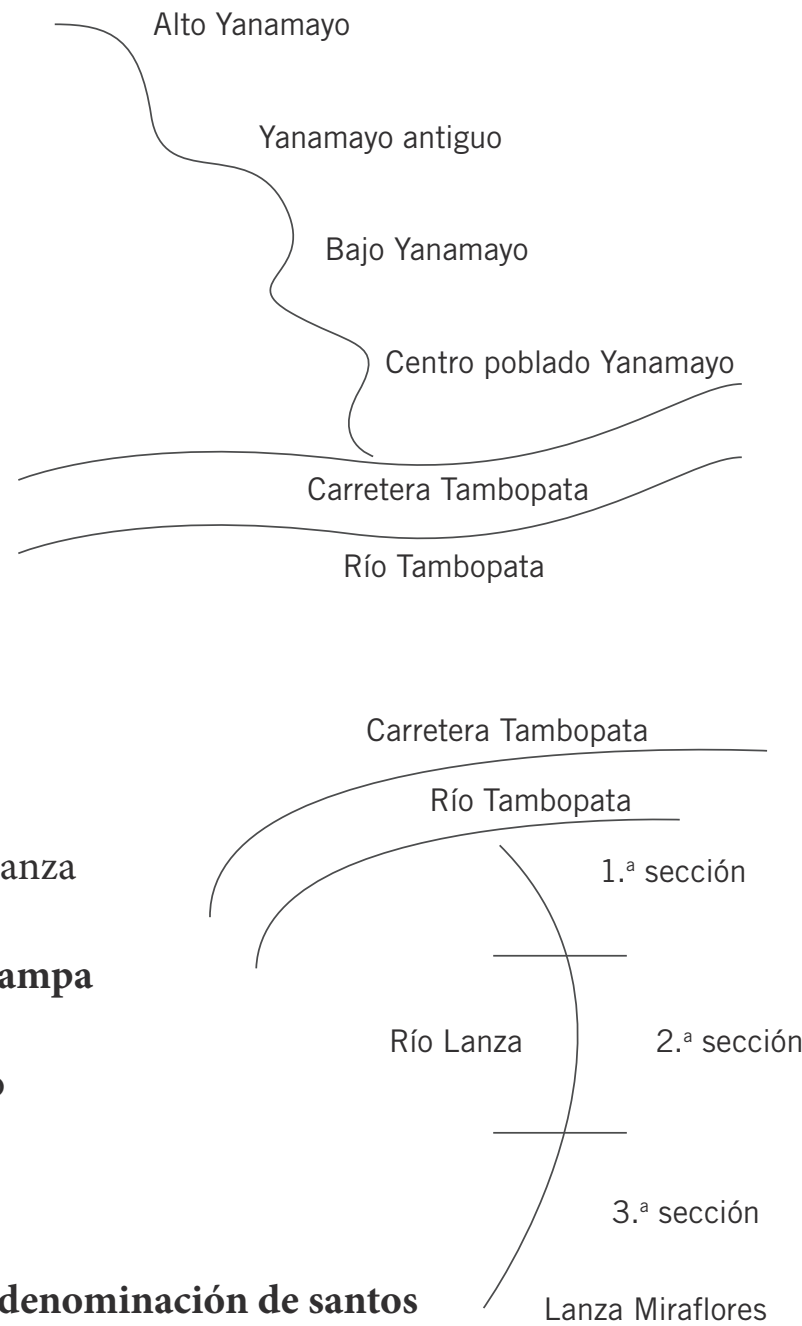
Topónimos de la cuenca del río Tambopata (Puno)

Santa Ana

Santa Rosa

San Juan del Oro

San Martín de Tambopata

San José de Muyuhuasi

San Guillermo

San Blas

San Rafael

San Benigno

Santa Fe

San Vicente

San Felipe

\subsubsection{En algunos casos toman nombres de}

personajes que poblaron antes en la zona.

Carlos San Carlos: personaje que pobló antes en época de cascarilla al morir le pusieron el nombre a ese lugar con el apelativo posterior de «San».

Victoria. La señora que pobló la zona, dedicándose a los cultivos de raizales.

Carmenpata. Una señora que tenía varios hijos, fue pobladora en la zona.

Rosario

Fermín

Alfonso Ugarte

Mamani

Martí. Compania que tenía fincas, caminos, operarios para explotacion de cascarilla. Markham. Recorrió el mundo, en el Perú 1852 - 18-54, 1860 - 1861. Introdujo semilla de cascarilla a la india y Ceilan (Srilanka) murió en 1916.

Távara

Larrabure y Correa

Zubieta

Fernández

Ego Aguirre

Asunto

Heath (Edwin R.). Explorador médico norteamericano (1839 - 1904) surcó los ríos de Amazonas, Madera, Mamoré y Beni, madre de Dios. Al río sonene denominan ahora río Heath. 
5.1.13. La mayoría de los nombres abarcan denominando categorías espaciales como el río, el centro poblado o sector en la parte alta llamada caserío, laguna, otro lugar similar, quebrada y otros. Sólo tenemos pocos nombres del lugar sin especificar río, quebrada, pampa.

Charuyo

Río Charuyo

San Benigno

Victoria

Río Victoria

Tambopata

\subsubsection{Como quebradas}

Huayco

Ccasasani

Mariposa

Marte

Tambopata

5.1.15. Nombre de lugares que están en proceso de extinción por haber pasado por más abajo la carretería, huaico, poca población y abandono del lugar

Martí, es reemplazado por Marte.

Versalles, antes era una mina de oro en el río Chaylluma.

Peñón de oro, ahora es Huacapata.

Tinri phawchinta, antes un lugar de descanso para tomar agua y ver a los tigres bañándose, ahora es un lugar abandonado y olvidado.

Palli phuju < «valle manantial» antes era una zona con varios manantiales, ahora por el embalse de la laguna San Ignacio, ya no tiene manantiales.

Huichullani - es río que antes era un poblado ahora ya no hay pobladores, y el nombre ya no se menciona. 
Topónimos de la cuenca del río Tambopata (Puno)

\subsubsection{Lugares que tienen varios nombres}

Fermin $\sim$ San Fermín $\sim$ Alto Valle $\sim$ Valle Futuro

Asata $\sim$ asata pampa $\sim$ asaat'a $\sim$ playa asata

Alto azata $\sim$ asatapata $\sim$ jasaat'a

Paujil pawji

Alto paujil alto paují $~$ paujipata

Paujil playa $\sim$ pawji playa $\sim$ paujilpampa $\sim$ pampa paujil

San Juan del Oro quriwayq'u (quebrada de oro ambaya) «el dorado» «valle yunga» Villa imperial de San Juan del Oro (1555) Alto Tambopata $\sim$ San Juan Pata $\sim$ aynacha $\sim$ montaña, los huarayos. Chunchos llamaban al río Tambopata bahuaja Bajuaja, poblaron hace miles de años, solo están de pasada hace 9 décadas Raimondi señala que en 1835 los salvaje bajaron del cerro Chunchucahuana que está en la cabecera de Botijani y mataron a una mujer y un hombre en Huacaychuru, que serían los primeros migrantes a Tambopata, Waldo Calderón afirma que llegaron en dos oportunidades del Puerto Astillero los tribus: ichuja, ticuri y huarayo, el último tribu en llegar fue Martín Gugajee con su indumentaria nativa y lengua, demostró ser cazador, el cerro Chunchucahuana sirvió para vigilar el avance de los chunchos.

El 19 de mayo de 1913, la Empresa Gomera fue atacado por cien guarayos que destruyeron el almacén de San Carlos y los cultivos, a raíz de este hecho la empresa abandonó el lugar, pues desde Londres comunicó el abandono ante una situación caótica, el gerente de dicha empresa se fue a Inglaterra.

Puju phuju.

Quiquira $\sim$ San Lorenzo de Quiquira $\sim$ Laccani $\sim$ San Lorenzo.

Huaycco $\sim$ Llinquini

Pampa grande $\sim$ pamparanti

Salvavidas salwawira San Lorenzo.

Carabaya caruaya (Cieza de León, 1551) Caraguaya (Hernández Girón, 1549)

Astillero Artillero

Heath Abuyama sonene

Chocal $\sim$ choca $\sim$ chuqui

Miraflores lanza lanza Miraflores

Huaranca $\sim$ waranja $\sim$ warankha

Cruz playa $\sim$ rusplaya

San Salvador $\sim$ chuquini 
Challuma $\sim$ chaylluma $\sim$ chälluma $\sim$ challuhuma $\sim$ challüma $\sim$ chilluma Torre Mamani $\sim$ torre alegre

\subsubsection{En otras lenguas}

Potzoago

Shohuiguensi

Sheujichana $\sim$ sihuchui

Echainapa

Parrotes

Sonene

Baguaja

Matehue

Yabroco

Chirluna

\subsubsection{Variación en la pronunciación}

\begin{tabular}{|c|c|c|c|}
\hline Aimara & Quechua & Castellano & Otra lengua \\
\hline $\begin{array}{l}\text { Phirminu } \\
\text { asaat'a } \\
\text { asaat'pampa } \\
\text { asaat'pata } \\
\text { pawji } \\
\text { pawjipata } \\
\text { pawji pampa pawji } \\
\text { playa } \\
\text { marti } \\
\text { lakani } \\
\text { challüma chälluma } \\
\text { tampupata aynacha } \\
\text { turri mamani } \\
\text { chukini } \\
\text { rusplaya } \\
\text { waranqa } \\
\text { jithi } \\
\text { salwawira } \\
\text { pamparanti } \\
\text { wayq'u } \\
\text { llimkini }\end{array}$ & $\begin{array}{l}\text { asata } \\
- \\
\text { - } \\
\text { pawjil } \\
\text { - } \\
\text { pawjiplaya } \\
\text { - } \\
\text { kikira } \\
\text { chaylluma } \\
\text { tambopata } \\
\text { turi mamani } \\
\text { chukini s. } \\
\text { salvador } \\
\text { rusplaya } \\
\text { waranja } \\
\text { jit } \\
\text { salwawira } \\
\text { - } \\
\text { wayku wayqu }\end{array}$ & $\begin{array}{l}\text { firmín } \\
\text { asata } \\
\text { playa asata } \\
\text { alto asata } \\
\text { Paujil } \\
\text { Alto Paujil } \\
\text { Playa paujil Pampa Paujil } \\
\text { Marte Martí } \\
\text { quiquira } \\
\text { challuma } \\
\text { Tambopata Montana, Alto } \\
\text { Tambopata } \\
\text { Torre Alegre } \\
\text { San Salvador } \\
\text { Cruz Playa } \\
\text { huaranca } \\
\text { Heath } \\
\text { Salvavida San Lorenzo } \\
\text { Pampa Grande } \\
\text { huayco }\end{array}$ & Baguaya \\
\hline
\end{tabular}


Topónimos de la cuenca del río Tambopata (Puno)

\section{Conclusiones}

La denotación es con la cosmopercepción y visión andina donde el espacio geográfico se interpreta por categorías duales: arriba (amsta, ataya, pata) abajo (aynacha, manqhi) centro (taypi, pampa).

La cosmovisión aimara continúa diferenciándose con los saberes andinos en la selva.

Hay adaptaciones de algunas lenguas (japunisa, unkucha, papapituca).

\section{Bibliografía}

Calizaya, J. (2006). EL Alto Tambopata. Puno, Perú: Speedy \& Service Pacific.

Carbajal, F. (1908). Expedición al Tambopata. Boletín de la Sociedad Geográfica de Lima, Tomo 23-4, 277-298.

Chichon, A. (1977). La lenta colonización del inambari y el Tambopata: Uso del espacio en la Selva Sur del Perú. En Perú, Problema Agrario. Lima, Perú: Sepia. Guevara, A. (1955). Apuntes sobre mi Patria (Tomo 3). Lima: H. G. Rozas.

Huayhua, F. (2009). Diccionario Bilingüe polilectal Aimara - Castellano - Aimara. Lima, Perú: Universidad Nacional Mayor de San Marcos.

Luna, M. (1954). La Colonización indígena del Valle de Tambopata. Lima, Perú: Dir. De Asuntos Indígenas.

Martínez, H. (1969). Las migraciones altiplánicas y la colonización del Tambopata. Lima, Perú: Centro de Estudios de Población.

Metraux, A. (1954). Informe sobre emigración interna y externa de los indios aymaras en el Valle de Tambopata. Ginebra: OIT.

Raimondi, A. (1910). Itinerario de los viajes de Raimondi. Boletín de la Sociedad Geográfica de Lima, Tomo 25-3, 65-108.

Stiglich, G. (1908). Viaje de Sandia a Chunchosmayo. En Boletín de la Sociedad Geográfica de Lima, Tomo 33-41, 355-393.

Torres, A. (1968). La meseta y el Lago Titicaca. Lima: Gráfica Colegio Unión.

Turpo, R. (2010). Monografía 1. Centro poblado de Yanamayo Sandia. Puno, Perú: Radio fM San Gabriel, Parroquia Santa Rosa de Lima.

Villalta, J. (1907). Expedición al Tambopata. Boletín de la Sociedad Geográfica de Lima, Tomo 21-4, 440-458. 